\title{
FORMATION OF THE PERSON AS A SUBJECT OF PEDAGOGICAL ACTIVITY
}

\section{Sayyora Saidjalalova}

Senior teacher of MSU named after M. V. Lomonosov Tashkent branch, e-mail: ogised_2006@mail.ru, orcid.org/0000-0002-7268-6481, Uzbekistan

\section{Zulfizar Karimova}

Senior teacher of MSU named after M. V. Lomonosov Tashkent branch, e-mail: zulfizar.karimova@yandex.com, orcid.org/0000-0003-1160-745X, Uzbekistan

\begin{abstract}
This article is devoted to the origin of the pedagogical profession. The main content of the pedagogical profession is the relationship with people. The activities of other representatives of "human-to-human" professions also require interaction with people, but here it is related to the best understanding and satisfaction of human needs.
\end{abstract}

Keywords: Pedagogical profession, society, modern understanding, education, humanforming, spiritual world.

\section{DOI: http://dx.doi.org/10.23856/2611}

\section{Introduction}

The meaning of the pedagogical profession is revealed in the activity carried out by its representatives and which is called pedagogical. It is a special kind of social activity aimed at transferring from elder generations to younger people the accumulated culture and experience, creating conditions for their personal development and preparing for the performance of certain social roles in society.

In ancient times, when there was no division of labor, all members of the community or tribe - adults and children - participated on an equal footing in the obtaining of food, which was the main reason for existence in those distant times. The transfer of experience accumulated by previous generations to children in the prenatal community was "woven" into labor activity. Having been included in it, children, from an early age, learned the methods of activity (hunting, gathering, etc.) and mastered various skills. And only with the improvement of tools, which made it possible to get food more, it became possible not to involve the sick and old members of the community. They were charged with being the keepers of fire and looking after the children.

Later, as the processes of conscious manufacture of tools of labor, which entailed the need for special transfer of labor skills, became more complicated, the elders of the clan - the most respected and wise by experience - formed, in the modern understanding, the first social group of educators, whose direct and sole responsibility was transfer of experience, care for the spiritual growth of the younger generation, its morality, preparation for life. So upbringing became the sphere of human activity and consciousness.

The origin of the pedagogical profession has objective grounds. The society could not exist and develop if the younger generation, replacing the older one, were forced to start all over again, without the creative development and use of the experience that it inherited.

Since the birth of the pedagogical profession, the teachers have, first of all, consolidated an educational, unified and indivisible function. The teacher is the master, the tutor. This is his civil, human destiny. 
The tasks that confronted the school changed significantly at different stages in the development of society. This explains the periodic transfer of emphasis from training to education and vice versa. As it is impossible to teach without providing educational influence, it is also impossible to solve educational problems without equipping students with a rather complex system of knowledge, skills and skills. The progressive thinkers of all times and peoples never opposed instruction and education. Moreover, they considered the teacher, first of all, as an educator.

The belonging of a person to a particular profession is manifested in the features of his activity and way of thinking. According to the classification proposed by E. A. Klimov, the pedagogical profession refers to a group of professions the subject of which is another person (Klimov, 2007). But the pedagogical profession is allocated, first of all, in the manner of the thoughts of its representatives, to an increased sense of duty and responsibility. In this regard, the pedagogical profession stands apart, standing out in a separate group.

The main difference from other professions such as "man-man" is that it relates both to the class of transforming and to the class of managing professions at the same time. Having as the goal of his activity the formation and transformation of the personality, the teacher is called upon to manage the process of its intellectual, emotional and physical development, the formation of its spiritual world.

The main content of the pedagogical profession is the relationship with people. The activities of other representatives of "human-to-human" professions also require interaction with people, but here it is related to the best understanding and satisfaction of human needs. In the profession of the teacher, the leading task is to understand the social goals and direct the efforts of other people to achieve them.

A teacher, like any other leader, should know and represent the activities of the students, the development process of which he supervises. Thus, the pedagogical profession requires a dual training - human studies and special.

So, in the profession of the teacher, the ability to communicate becomes a professionally necessary quality.

The peculiarity of the pedagogical profession is that it is humanist, collective and creative in nature.

Two social functions have historically been entrenched for the pedagogical profession adaptive and humanistic ("human-forming").

Adaptive function is associated with the adaptation of the student, the learner to the specific requirements of the modern socio-cultural situation, and the humanistic one with the development of his personality, creative individuality.

On the one hand, the teacher prepares his students for the needs of the given moment, for a certain social situation, for specific demands of society. But on the other hand, he, objectively remaining the guardian and conductor of culture, carries a timeless factor. Having as an objective the development of the personality as the synthesis of all the riches of human culture, the teacher works for the future.

The basis for the success of the teacher is the spiritual wealth and generosity of his soul, the upbringing of the senses and the high level of the general emotional culture.

Pedagogical activity, like any other, has not only a quantitative measure, but also qualitative characteristics. The creative nature of pedagogical activity is its most important feature. But unlike creativity in other spheres (science, technology, art), the creativity of the teacher does not aim to create a socially valuable new, original, because his product always remains the development of the individual. Of course, a creative teacher, and especially a 
pedagogue-innovator, creates his own pedagogical system, but it is only a mean for obtaining the best result in the given conditions.

\section{Conclusions and suggestions}

The creative potential of a teacher's personality is formed on the basis of his social experience, psychological, pedagogical and subject knowledge, new ideas, skills and abilities that enable him to find and apply original solutions, innovative forms and methods, and thereby improve the performance of his professional functions.

Only an erudite and specially trained teacher on the basis of a deep analysis of emerging situations and awareness of the essence of the problem through creative imagination and mental experiment is able to find new, original ways and ways to solve it.

But experience shows that creativity comes only and only to people who conscientiously treat work, constantly strives to improve professional qualifications, replenish knowledge and learn the experience of the best schools and teachers. In this regard, awareness of the general and special in different types of pedagogical activity, as well as the integrity of the pedagogical process, is the most important characteristic of the pedagogical thinking of the modern teacher.

\section{References}

Klimov, E. A. (2007). Psychology professional self: A textbook for high schools. Moscow: Academy. [in Russian].

Sukhomlinsky, V. A. (1981). Selected pedagogical works. Tom 3. Moscow: Pedagogy. [in Russian].

Tolstoy, L. N. (1953). Pedagogical works. Moscow: Uchpedgiz. [in Russian]. 